\title{
Retraction Note to: Canine transmissible venereal tumor and seminoma: a cytohistopathology and chemotherapy study of tumors in the growth phase and during regression after chemotherapy
}

\author{
J. Javanbakht ${ }^{1}$ - B. Pedram ${ }^{2}$ - M. R. Taheriyan ${ }^{3}$ - F. Khadivar $^{4}$ - S. H. Hosseini ${ }^{5}$ \\ F. S. Abdi ${ }^{6}$ - E. Hosseini ${ }^{7}$ - M. Moloudizargari ${ }^{8}$ - S. H. Aghajanshakeri ${ }^{8}$. \\ S. Javaherypour ${ }^{8} \cdot$ R. Shafiee ${ }^{4} \cdot$ R. Emrani Bidi ${ }^{9}$
}

Published online: 5 November 2016

(C) International Society of Oncology and BioMarkers (ISOBM) 2016

\section{Retraction Note to: Tumor Biol (2014) 35:5493-5500 \\ DOI 10.1007/s13277-014-1723-5}

This article has been retracted at the request of the Editor-in-Chief, the International Society of Oncology and BioMarkers (ISOBM) and the Publisher per the Committee on Publication Ethics guidelines. The article shows evidence of irregularities in authorship during the submission process, irregularities in the methods section, there is strong reason to believe that the peer review process was compromised and the au-

The online version of the original article can be found at http://dx.doi.org/ 10.1007/s13277-014-1723-5.

\section{J. Javanbakht}

javadjavanbakht@ut.ac.ir

1 Department of Pathology, Faculty of Veterinary Medicine, Tehran University, Tehran, Iran

2 Department of Pathobiology, Susangerd Branch, Islamic Azad University, Susangerd, Iran

3 Department of Animal Science, College of Agriculture, Islamic Azad University, Kashmar Branch Kashmar, Iran

4 Graduate, Faculty of Veterinary Medicine, Tehran University, Tehran, Iran thors have plagiarized substantial parts from the following article:

D. Nak, Y. Nak, I. T. Cangul, B. Tuna, A Clinicopathological Study on the Effect of Vincristine on Transmissible Venereal Tumour in Dogs, Journal of Veterinary Medicine Series A. 2005; 52:7 366-370

DOI: $10.1111 / j .1439-0442.2005 .00743 . x$

As such the validity of the content of this article cannot be verified.
5 Faculty of Veterinary Medicine, Graduate Student of Islamic Azad University of Garmsar, Garmsar, Iran

6 Science and Research Branch of Tehran, Small Animal Internal Medicine Resident of Islamic Azad University, Tehran, Iran

7 Faculty of Para Veterinary Medicine, Ilam University, Ilam, Iran

Student of Veterinary Medicine, Faculty of Veterinary Medicine, Urmia University, Urmia, Iran

EA1274 (M2S) laboratory, Department of Pharmacy, University of Rennes 1, Rennes, France 